Article

\title{
EU Climate and Energy Policy: How Myopic Is It?
}

\author{
Jana Gheuens ${ }^{1, *}$ and Sebastian Oberthür ${ }^{1,2}$ \\ ${ }^{1}$ Brussels School of Governance, Vrije Universiteit Brussel, Belgium; E-Mails: jana.gheuens@vub.be (J.G.), \\ sebastian.oberthuer@vub.be (S.O.) \\ ${ }^{2}$ Centre for Climate Change, Energy and Environmental Law, University of Eastern Finland, Finland \\ * Corresponding author
}

Submitted: 30 March 2021 | Accepted: 1 September 2021 | Published: 30 September 2021

\begin{abstract}
This article investigates the shortsightedness or myopia of recent climate and energy policy (CEP) in the EU. To this end, it develops and applies a measurement tool of short-termism composed of four key criteria: (1) the reflection of sciencebased long-term thinking in the policy process and its output; (2) the degree to which mid-term greenhouse gas emission targets and accompanying policies align with science-based long-term objectives; (3) the stringency of the legislation; and (4) its adaptability. We use these criteria to assess the levels of short-termism of the EU's 2020 and 2030 CEP frameworks and the (still evolving) European Green Deal (EGD). Overall, we find that the level of myopia of EU CEP has fluctuated and has advanced far less than the development of the nominal mid-term emission targets might suggest. The EGD's 55\% emission reduction target for 2030 only constitutes a return to the levels of alignment with science-based long-term objectives existing in the 2020 Package (making good on the regression of the 2030 Framework). It is primarily due to the maturing of long-term thinking and a ratcheting mechanism, that EU climate policy under the EGD can be considered less myopic than the 2020 Package (although the assessment remains preliminary pending the adoption of further implementing legislation). These findings lay the ground for future research that not only investigates reasons for the general myopia of (EU) climate policy, but also the drivers of the fluctuations over time.
\end{abstract}

\section{Keywords}

2020 Package; 2030 Framework; ambition; effort sharing; emissions trading; European Climate Law; European Green Deal; myopia

Issue

This article is part of the issue "Climate Governance and the European Green Deal in Turbulent Times" edited by Claire Dupont (Ghent University, Belgium) and Diarmuid Torney (Dublin City University, Ireland).

(C) 2021 by the authors; licensee Cogitatio (Lisbon, Portugal). This article is licensed under a Creative Commons Attribution 4.0 International License (CC BY).

\section{Introduction}

In the twenty-first century, the EU has significantly developed its climate and energy policy (CEP), most notably through several policy packages. The 2020 Climate and Energy Package (2020 Package), adopted in 2009, established and implemented a greenhouse gas (GHG) emission reduction target of $20 \%$ by 2020 . In 2018, the 2030 Climate and Energy Policy Framework (2030 Framework) revised this target to $40 \%$ by 2030 . In the last step so far, the European Climate Law adopted under the European Green Deal (EGD) in 2021, upgraded the 2030 mitiga- tion target to $55 \%$ (while further implementing legislation is forthcoming) to better align the EU's commitments with the temperature goal of the Paris Agreement, namely, to limit the increase of global average temperature to $2{ }^{\circ} \mathrm{C}$ or even $1.5^{\circ} \mathrm{C}$ compared with pre-industrial times. Over the same timeframe, the EU's long-term target has also evolved from a political commitment to reducing GHG emissions by $80-95 \%$ by 2050 made in 2009 to a binding target of climate neutrality or netzero emissions by 2050 enshrined in the Climate Law. In parallel with advancing its emission targets, the EU has also developed the surrounding legislative framework, 
including the EU Emissions Trading Scheme (ETS) covering the power and industry sectors, an Effort Sharing among member states regarding the non-ETS sectors, the Renewable Energy Directive, the Energy Efficiency Directive and more (on EU CEP and its evolution, see e.g., Boasson \& Wettestad, 2013; Delbeke \& Vis, 2019; Kulovesi \& Oberthür, 2020).

A rich literature has explored various aspects of EU CEP. Amongst several themes, scholars have analysed: the development of EU climate policy, its implementation and effectiveness, its ambition, its innovation, the EU's role as an international climate leader, and individual climate policy instruments and packages (e.g., Boasson \& Wettestad, 2013; Burns, 2019; Dupont, 2016; Rayner \& Jordan, 2016). This is not the place for a comprehensive review of the achievements and shortcomings of this literature and its many branches. Rather, we note that hardly any contributions to this literature have, as of yet, diachronically assessed to what extent EU CEP, and its mid-term targets and related policy frameworks in particular, has been in line with scientifically-derived long-term objectives.

Beyond the literature on EU CEP, scholars have investigated the role of time in climate politics. Short-term time horizons and the focus on immediate interests form a key component of the conceptualization of climate change as a "superwicked problem," having so far led to largely inadequate climate policies (Levin et al., 2012). Similarly, Hovi et al. (2009) have argued that the time inconsistency between short-term costs of climate policies and long-term benefits resulting from them, impedes effective climate protection. Hence, temporal asymmetries between short-term policy action ("political time," e.g., electoral cycles or dynamics of international institutions) and long-term impacts ("deep time," geological timescales) hamper climate decision-making (Galaz, 2019). Furthermore, literature on "democratic myopia" has explored the shortsightedness of politics more generally (and only partially with respect to climate policy; see Cseh, 2019) as resulting from the institutional structures of contemporary democratic political systems (see Finnegan, 2019) and associated behavioral mechanisms and short-term interests (e.g., Jacobs, 2016; Mackenzie, 2016). In line with the problem analysis, these diverse contributions explore similar potential solutions, namely adapting the design of (climate) policies (to strengthen their path dependency; see Levin et al., 2012) and the institutional structures of political systems (e.g., reinforcing the agonistic aspects of democracy, as in Machin, 2019; turning to deliberative forms of democracy, as in Dryzek \& Niemeyer, 2019; or even potentially constraining democracies, as in Beckman, 2008). Surprisingly, however, few contributions to the mentioned literatures have empirically examined the degree of shortsightedness or "myopia" of climate policy as a key foundation for investigating the reasons for such myopia and possible remedies. Additionally, myopia literature has, so far, remained focused on the national level.
As a result, any changes of the level of myopia over time or the presence of myopia at the EU level have hardly been explored.

Against this backdrop, this article examines the level of myopia/shortsightedness (or farsightedness) of EU CEP from the 2020 Package to the EGD. How myopic has EU CEP been, and has its level of short- or farsightedness changed over time? Investigating these questions promises to make a twofold contribution to the aforementioned scholarship. First, it offers a fresh systematic assessment of EU CEP which advances on the established focus on ambition by taking a long-term perspective that pays particular attention to intertemporal trade-offs. Second, our analysis proposes an approach to the systematic investigation/determination of the level of myopia of (climate) policy as an essential basis for research on temporal asymmetries, time inconsistencies and "democratic" myopia. This provides the ground for systematic comparisons across countries and time as an important basis for advancing explanatory analyses, which we have to leave for future research.

We argue that EU CEP has, overall, remained shortsighted, but with significant variation over time and across different criteria. Our assessment indicates that the myopia of EU CEP has declined far less than the development of the nominal mid-term emission reduction targets-from $20 \%$ to $40 \%$ to $55 \%$-might suggest. The $55 \%$ target under the EGD only returned to the levels of the 2020 Package (making good on the regression of the 2030 Framework). It is primarily due to the maturing of long-term thinking and a ratcheting mechanism, that EU CEP under the EGD can be considered less myopic than the 2020 Package (although the assessment remains preliminary pending the adoption of further implementing legislation).

In the following, we develop our argument in three steps. The next section first lays out our framework for assessing the level of myopia of EU CEP featuring four key criteria. Subsequently, we apply these criteria to appraise the level of myopia of EU CEP from the 2020 Package over the 2030 Framework to the evolving EGD. Lastly, we discuss the main findings, draw conclusions and look ahead to follow-up research.

\section{Myopia of EU Climate Policy: Assessment Framework}

Building on the relevant literature, we suggest four key criteria for assessing the level of myopia of EU CEP over time. We propose to investigate to what extent: (1) a long-term perspective in line with science was explicitly reflected in the legislative process and its output; (2) the mid-term emission reduction targets and accompanying policies have been in line with long-term objectives in accordance with science; (3) the governance framework has been "stringent" in demanding actors to adapt their behavior; and (4) ratcheting mechanisms for further developing mitigation targets and the governance 
framework in line with science (adaptability) have been included. Overall, we consider myopia a property of a policy (both process and output), hence our focus on the EU's legislative documents. While this may connect to the myopia of actors, investigating the latter would move towards explanation, which is beyond the scope of this article and may be part of future research (see also below).

First, we analyze to what extent a long-term perspective was reflected in the decision-making process and its output. This criterion serves to provide a first insight into the importance and understanding of the long term in the legislative process and the resulting legislation. Three aspects appear to be particularly relevant in this respect, namely: (1) whether any long-term objective is mentioned; (2) whether the mid-term emission reduction target is related to the long-term target and trajectory; and (3) whether the long-term target is derived from science. This third sub-criterion is meant to capture the quality of the long-term perspective that is likely to be deficient without a firm basis in science. To assess these three aspects, we examine the adopted legislative texts related to the emission reductions and their implementation, as well as the legislative proposal by the European Commission and the positions expressed by the European Parliament and the Council of Ministers (and any related pronouncements of the European Council).

Second, we appraise the degree to which the midterm target pursued closes the gap between a baseline scenario and an ideal, farsighted mitigation trajectory. While the identification of the existing emission target is straightforward, assessing the other two reference values - the baseline and the ideal ambitionraises important issues (Grant et al., 2020).

The baseline scenario denotes the emission trajectory toward the relevant target year that was expected under existing policies prior to the political decision on the target. The calculation of such a hypothetical emission trajectory is not an exact science, not least because it is based on assumptions about uncertain future developments of relevant framework conditions, such as economic growth. Nevertheless, the European Environment Agency has, since 2003, published the most authoritative baseline scenarios for the EU (projections with existing measures) in its "Trends and Projections" reports. We thus use these as our baseline scenarios.

At the other end of the spectrum lies the ideal, farsighted ambition of EU mitigation targets. What target should the EU, according to the latest science at the time of decision-making, have aimed at? While science can advise on which global emission scenarios have a higher or lower likelihood of ensuring global temperature increase stays below $2{ }^{\circ} \mathrm{C}$ (or even $1.5^{\circ} \mathrm{C}$ ), varying equity or fairness criteria lead to different results as to the share of individual actors depending on historical and current responsibility, economic and technological capabilities, etc. (Hayward, 2012; Williston, 2019). In this respect, we base our discussion on the principle of "common but differentiated responsibilities and respective capabilities" enshrined in the United Nations Framework Convention on Climate Change (UNFCCC) and its Paris Agreement (Robiou du Pont et al., 2017). Accordingly, both responsibility and capability need to be considered. Since, in practice, actors with high historical responsibility (e.g., the US and the EU) generally also possess high capacity to mitigate climate change, we take into account studies that include both responsibilities and capabilities or only capabilities, in order to identify scenarios of farsighted ambition.

In assessing the mid-term target, we additionally examine relevant accompanying provisions of the policy instruments adopted to implement it. Two types of flexibilities may be considered. First, some provisions may allow EU member states to balance over-and underachievements between them or across time (borrowing emission allowances from the future, banking past emission reductions). These flexibilities do not affect the overall target, but may reduce the likelihood that it is overachieved. Of greater concern, flexibilities that allow member states to offset their emissions by domestic or international carbon removals/credits (e.g., from forests) de facto reduce and water down the emission reduction target (see McLaren, 2020). By contrast, accompanying provisions on renewable energy or energy efficiency have the potential to provide additional impetus for emission reductions, potentially leading to overachievement of the emission target (despite concerns that they might interfere with the proper functioning of other policy instruments such as the ETS; Rayner \& Jordan, 2016).

Beyond the ambition of the target, we examine other aspects of the policy design of the legislative measures particularly relevant for myopia. As covering all aspects of policy design from the policy instrument choice and policy mixes to design processes and the actors involved in the policy design (see Howlett \& Mukherjee, 2018) is beyond the scope of this article, we focus on two components that are particularly pertinent for our purposes: the stringency and adaptability of the legislation. A certain degree of stringency or bindingness is required for the targets to be achieved across different policy cycles (i.e., electoral cycles or terms of office). Low stringency would then indicate shortsightedness as the targets will be less likely achieved or more likely overturned or watered down in a following policy cycle. To examine stringency, we base our assessment on the framework developed by Oberthür (2019) on the basis of literature on hard versus soft law as well as the bindingness and legalization of international governance. He introduces four criteria: (1) the formal status of the legislation (i.e., whether it is formally binding); (2) the nature of the obligations (i.e., substantive or procedural); (3) the prescriptiveness and precision of the rules and obligations; and (4) the means available to promote accountability and effective implementation (e.g., monitoring and reporting, response to non-compliance). 
Furthermore, adaptability is required to avoid a lockin of shortsighted policies. The need for mechanisms for ratcheting and further developing CEP over time arises because most emission targets and accompanying climate governance frameworks have historically remained deficient (e.g., Climate Action Tracker, 2019). In addition, new scientific knowledge may emerge, and other developments may affect mitigation trajectories. Thus, the policy framework needs to include mechanisms to regularly review and strengthen existing targets, as appropriate, in line with science. As a prime example, the Paris Agreement includes various provisions that are jointly referred to as a "ratcheting" or "ambition mechanism" (Brun, 2016; Torney \& O’Gorman, 2020). Key features of such an ambition mechanism include: (1) the scheduled regular review and further development of existing targets and measures; (2) the orientation towards strengthening (rather than a weakening); and (3) the establishment of science as a benchmark (Torney \& O'Gorman, 2020). Taken together, these elements may, beyond the emission targets themselves, serve to indicate the extent to which the governance framework is oriented towards the long term and farsighted.

Overall, the two criteria of the ambition of mid-term targets and the stringency of the related legislative measures constitute the substantive core of our assessment of the myopia of EU CEP over time. They determine the compatibility of EU CEP with long-term science-based requirements. Whether deliberate or not, lack of compatibility can be interpreted as myopia/shortsightedness, unless an appropriate reasoning is provided (e.g., lack of feasibility of science-based long-term requirements). The existence and design of a ratcheting mechanism forms a complement as a third criterion to be taken into account in addition to the two aforementioned ones. Furthermore, examining whether and how long-term considerations have been explicitly reflected in the political process and its output allows us to determine whether any shortcomings on the other criteria may be due to the neglect of the long term, result from deficiencies in the long-term perspective (e.g., a disregard of science), or are in fact acknowledged (e.g., as mentioned above, by providing appropriate reasons). Taken together, the four criteria hence enable us to assess the myopia of EU CEP over time, including both the substance of the policy and the framing of its time horizon.

\section{Assessing the EU's Level of Myopia Over Time}

We apply our analytical framework to the main milestones in the development of EU CEP legislation: the 2020 Package, the 2030 Framework and the EGD. These overarching legislative frameworks set out the EU's midterm GHG emission reduction targets, which have been divided into a target for the sectors covered by the ETS Directive (principally industry and power) and a target for the non-ETS sectors (including transport, buildings, and agriculture) covered by the Effort Sharing
Decision/Regulation. While the overall targets relate to 1990 as the baseline, the ETS and non-ETS targets are calibrated against 2005 , for which verified data are available (Delbeke \& Vis, 2019). Other key elements of the aforementioned legislative frameworks include the Renewable Energy (RE) Directive, the Energy Efficiency (EE) Directive and, newly introduced in the 2030 Framework, the Regulations on Land Use, Land Use Change and Forestry (LULUCF) and on the Governance of the Energy Union and Climate Action (hereafter Governance Regulation; Delreux \& Happaerts, 2016; Kulovesi \& Oberthür, 2020). As the legislation of the EGD is still under development at the time of writing, the assessment focuses on the European Climate Law that (among other things) enshrines both a strengthened 2030 emission target and climate neutrality by 2050 in law.

\subsection{Package}

Adopted in 2008/2009, the 2020 Package established the EU's target of a $20 \%$ GHG emission reduction by 2020 compared to 1990 . To implement this target, the ETS Directive and the Effort Sharing Decision aimed to reduce GHG emissions in their respective sectors by $21 \%$ and $10 \%$ (compared to 2005; EU, 2009a, 2009c). Additionally, the RE Directive established binding member state targets towards increasing the share of RE in the EU's final energy consumption to $20 \%$, and the EE Directive (adopted in 2012) pursued an indicative target of a 20\% EE improvement (EU, 2009b, 2012; Oberthür \& Pallemaerts, 2010; Rayner \& Jordan, 2016). The emission reduction target was to be upgraded to $30 \%$ if other developed countries and more economically advanced developing countries took comparable and adequate action according to their responsibilities and capabilities (an upgrade that did not materialize).

Neither the legislation nor the legislative process provide evidence for adequate long-term thinking. As a result of the proposal by the Commission and suggestions by the European Parliament and the European Council, the legislation referred to long-term objectives of a global GHG emission reduction of $50 \%$ and a reduction of $60-80 \%$ for developed countries by 2050 (EU, 2009a, 2009c; European Commission, 2008a, 2008b; European Council, 2007; European Parliament, 2008a, 2008b). However, the scientific basis of these targets was-beyond mentioning "the Intergovernmental Panel on Climate Change (IPCC)" - not clearly argued. Perhaps even more importantly, it was unclear how the EU's 2020 target of $20 / 30 \%$ would fit in the long-term trajectory. Overall, it would appear that the long-term emission targets referred to were based on the IPCC's report from 2001 (Intergovernmental Panel on Climate Change [IPCC], 2001) rather than its then most recent report (IPCC, 2007); in other words, the scientific basis was outdated.

Regarding ambition, the $20 \%$ emission reduction target, on the one hand, significantly advances the baseline scenario of a $5 \%$ emission increase as estimated by the 
European Environment Agency (with existing measures; see European Environment Agency, 2007). On the other hand, this target falls short of what-according to the IPCC-developed countries would have had to reduce (25-40\% below 1990 levels by 2020; see IPCC, 2007) and the EU's fair share: Available studies taking into account responsibility and capability suggested that the EU's fair share would fall into the upper part of the indicated range (30-40\%; see den Elzen \& Höhne, 2008; Rogelj et al., 2010; Winkler et al., 2009). As a result, the $20 \%$ target closed the 35-45 percentage point gap between the baseline $(+5 \%)$ and the required emission reductions (30-40\%) by close to two-thirds ( 25 of 35-45 percentage points $=55 \%-71 \%$ advancement; see Figure 1 ). An upgrade of the target to $30 \%$ would have aligned it with the lower end of the required range: It would have closed the gap by $78-100 \%$ (35 of 35-45 percentage points). Additionally, the target was somewhat reduced because ETS installations were allowed to use international emission credits to some extent. Several other flexibilities included in the package reduced the pressure to reduce emissions, most importantly the possibility for member states to bank past and borrow future emission allowances (5\%) under the Effort Sharing Decision and to trade such allowances between them (EU, 2009a, 2009c; Oberthür \& Pallemaerts, 2010). Furthermore, free allocation of ETS emission allowances to industries in international competition has been subject to criticism for slowing down emission reductions (Oberthür \& Pallemaerts, 2010). Counterbalancing these effects, action on RE and $\mathrm{EE}$ has served to bolster emission reduction efforts. As a result, an overachievement of the $20 \%$ target was soon projected (European Environment Agency, 2010).

Following Oberthür (2019), the 2020 Package possesses a relatively high degree of stringency. It is firmly rooted in instruments of EU law (regulations, directives, decisions). Member states have binding national targets for both emissions (under the Effort Sharing Decision) and RE (under the RE Directive), and emissions of industry and the power sector are directly controlled under the ETS Directive. The package combines these precise substantive obligations with procedural obligations, including for member states to elaborate plans and report on implementation and progress. The key obligations are, with some circumscribed limitations, precise and prescriptive with few flexibilities. Finally, the package can in large part rely on the general accountability and implementation mechanisms under EU law, in particular infringement proceedings. In addition, it possesses several specific means, such as evaluation of progress by the Commission, penalties for non-compliance under the ETS and specific consequences for any member state exceeding its emission allocation under the Effort Sharing Decision: a deduction of 1.08 tonnes of $\mathrm{CO}_{2}$ for every excess tonne, the requirement to develop a corrective action plan, and a temporary suspension to transfer emission allocations to another member state (Lacasta et al., 2010; Oberthür, 2019).
Lastly, the package included few measures towards adaptability. Most importantly, the 2020 emission reduction target could be raised to $30 \%$ if other developed countries and economically more advanced developing countries committed to taking strong action (see above). This would happen through the ordinary legislative procedure. Furthermore, several provisions for revising the different elements of the package were included; for example, the Commission could make additional legislative proposals to help the member states achieve their commitments under the Effort Sharing Decision after assessing its overall implementation (EU, 2009c, Art. 6). However, there was no clear schedule for the review and further strengthening of existing targets and measures and no clear link with science as a benchmark in this respect.

Overall, the 2020 Package displayed a relative farsightedness. The 2020 emission target closed the gap between the baseline scenario and the ideal scenario by about two-thirds, while a relatively high degree of stringency supported its effective implementation. To the limited extent that the Package reflected a long-term perspective, it was based on outdated science. At the same time, it lacked a dedicated ratcheting mechanism (so that no upgrading of the target was considered even though the $20 \%$ reduction was already realized in 2014).

\subsection{Framework}

Initiated in 2013/2014 and concluded in 2018/2019, the 2030 Framework aimed at a GHG emission reduction of at least $40 \%$ by 2030 compared to 1990 levels. The framework contained the amended ETS Directive (43\% reduction compared to 2005) and the Effort Sharing Regulation (30\% reduction compared to 2005), complemented by the amended RE Directive with a target of $32 \%$ for the share of RE in final energy consumption and the EE Directive with a target of a $32.5 \%$ improvement in EE (Kulovesi \& Oberthür, 2020). Other new key instruments included the LULUCF Regulation and the Governance Regulation, alongside a set of revisions of instruments governing the electricity market (EU, 2018b, 2018d; Kulovesi \& Oberthür, 2020).

A certain degree of long-term thinking is reflected in the legislation (especially in the Effort Sharing Regulation, the ETS Directive, and the Governance Regulation). Referring to the Paris Agreement's goal of limiting global temperature increase to $2{ }^{\circ} \mathrm{C}$ (preferably $1.5^{\circ} \mathrm{C}$ ), the EU set out to reach an $80-95 \%$ emission reduction by 2050 , net-zero as early as possible and negative emissions thereafter (EU, 2018a, 2018b, 2018c, 2018d). Having said that, the pathway towards the 2050 goal, how the $40 \%$ target fits in it, and the scientific basis for it (beyond stating "in the context of the IPCC") remain unspecified. While the $80-95 \%$ emission reduction in effect stems from the IPCC's 2007 report (and hence was again quite dated; see IPCC, 2007), the long-term targets included had been proposed by the Commission and 
the European Parliament (European Commission, 2016; European Parliament, 2017, 2018). The Parliament even argued for net-zero emissions by 2050 and negative emissions thereafter, and it proposed to task the European Commission with calculating a global carbon budget, and the EU's fair share in it, to guide the long-term trajectory (European Parliament, 2018).

We consider that the 2030 emission target closed the gap to what would ideally be required by less than half. As the IPCC did not formulate any benchmark mitigation ranges for 2030, we have derived them from scenarios that take either both responsibility and capability or at least capability into account (see Section 2). We have identified five scenarios that have applied these equity principles to calculate the EU's fair share, out of a wider range of scenarios using varying or no equity principles. They encompassed a range from $52.4 \%$ to 90\% GHG emission reduction compared to 1990 levels (Averchenkova et al., 2014; Meinshausen et al., 2015; Robiou du Pont et al., 2017). Since the three middle scenarios fell within a range of $64 \%$ to $67.9 \%$ emission reduction, we consider $60-70 \%$ an ideal range for the EU. According to the European Environment Agency, measures existing prior to the first pronouncement of the $40 \%$ reduction target in 2014 would have resulted in a baseline emission reduction of $22 \%$ by 2030 (European Environment Agency, 2014). Consequently, the adopted $40 \%$ target closed $37.5-47.4 \%$ of the gap between the baseline (22\%) and the required target range (60-70\%; see Figure 1).

Furthermore, the strengthened RE and EE targets (and accompanying rules) have been balanced by enhanced flexibilities. The 2030 Framework introduced several additional flexibilities, while largely keeping existing flexibilities or even expanding them (e.g., an increased borrowing limit of $10 \%$ between 2021-2025). In particular, member states were allowed to offset a certain amount of their emissions under the effort sharing with ETS allowances (up to 100 million allowances) and LULUCF credits (up to 280 million net removals; EU, 2018c; Kulovesi \& Oberthür, 2020). If fully exploited, the LULUCF credits could reduce the $40 \%$ target by close to three percentage points. In contrast, the Commission calculated that the full implementation of the RE and EE targets should lead to a significant overachievement of the $40 \%$ emission target toward $45-46 \%$ (European Commission, 2018; Kulovesi \& Oberthür, 2020).

At the same time, the stringency of the 2030 Framework is at a similar level as that of the 2020 Package (EU, 2018e, 2018f; Oberthür, 2019). On the one side, the bindingness suffered a set-back with the replacement of binding national targets for RE with a collectively binding target at the EU level. On the other side, the Governance Regulation strengthened member states' procedural obligations to prepare integrated National Energy and Climate Plans (including details on policies and measures) and long-term strategies as well as to report on progress in implementation (EU, 2018d;
Kulovesi \& Oberthür, 2020). Also, it upgraded the powers of the European Commission to monitor and promote implementation, and introduced a formula for the calculation of indicative national RE targets. Overall, these opposing trends can be considered to have cancelled each other out so that the stringency remained largely at the same level (Oberthür, 2019).

Furthermore, advancing beyond the 2020 Package, the 2030 Framework introduced a schedule for review and potential upward revision of the package (EU, 2018d; Torney \& O'Gorman, 2020). Strongly linked to the five-year global stocktake under the Paris Agreement in which countries collectively assess their progress towards the agreement's goals, the various legislative instruments foresee a review and potential upgrade around 2023 (and every five years thereafter). In addition, the Governance Regulation establishes that National Energy and Climate Plans are regularly updated and further developed every five years and requires the Commission to prepare a long-term strategy for the EU. This constitutes an opening for more long-term planning and the embedding of periodic reviews into a long-term decarbonization trajectory-without yet providing for such a trajectory and a related process that would clearly establish science as a benchmark (EU, 2018d; Kulovesi \& Oberthür, 2020; Torney \& O'Gorman, 2020).

Overall, the myopia of the 2030 Framework can, despite some opposing trends, be considered to have increased compared with the 2020 Package. The mitigation ambition pursued closes the gap towards effective climate protection in a long-term perspective less than half (down from about two-thirds) and was further softened by newly introduced flexibilities and offsets. While its stringency remained roughly at the same level, the 2030 Framework did progress on adaptability by establishing a ratcheting mechanism, which can be linked to a stronger explicit reflection on a longer-term perspective in the policy process and its output. This positive development remains, however, insufficient for balancing the significant regress on mitigation ambition.

\subsection{European Green Deal}

Launched by the von der Leyen Commission in 2019 as the EU's growth strategy to make its economy sustainable, the EGD aims at reaching climate neutrality (net-zero emissions) by 2050. As a central piece of the EGD, the Council and the European Parliament agreed on a European Climate Law in April 2021 (EU, 2021). This Climate Law enshrines an enhanced GHG emission reduction target for 2030 of $55 \%$ and the 2050 climateneutrality target. A fuller legislative package implementing the 2030 target (known as the "Fit for 55" package), including revisions of the ETS Directive, the Effort Sharing Regulation, the RE and EE Directives, was proposed in July 2021 and remains to be adopted at the time of writing. Thus, the analysis in this section focuses on the ambition, the long-term perspective and the ratcheting 
mechanism addressed in the Climate Law, while the stringency of the governance framework will largely depend on the Fit for 55 package still to be enacted.

The Climate Law more strongly reflects long-term thinking than the 2030 Framework, but still leaves room for significant further improvement. First, the Law binds the mid-term 2030 emission reduction target of net 55\% together with the long-term 2050 climate-neutrality target, along with a prospect of achieving negative emissions thereafter (EU, 2021). However, the pathway towards net-zero emissions in 2050 and the logic for the 2030 target on the trajectory to 2050 remains to be specified. Also, beyond general references to the IPCC $1.5^{\circ} \mathrm{C}$ Report (IPCC, 2018), it is not clear how the new targets align with science. This outcome resulted from the slightly diverging positions of the European institutions involved in the legislative process (Council of the European Union, 2020; European Commission, 2020; European Parliament, 2020). Especially the European Parliament argued for further strengthening the longterm perspective by requesting each member state to achieve negative emissions from 2051, and determining a Union carbon budget of $48 \mathrm{Gt} \mathrm{CO}_{2}$ equivalent for the period 2018-2050 (based on prior Commission calculations). Nevertheless, similar to the other institutions, the exact scientific basis for its long-term objectives was not further specified.

Concerning ambition, the heightened 2030 emission reduction target enhances farsightedness compared to the 2030 Framework, even though the baseline has increased in the meantime. Since the EGD emerged shortly after the finalization of the 2030 Framework, the same studies remain relevant. Hence, the EU's 2030 emission reduction target should have ideally amounted to $60-70 \%$. At the same time, the baseline scenario increased to $36 \%$ by 2030 because of the progress in implementing the 2030 Framework (European Environment Agency, 2019). Therefore, the $55 \%$ target closes $55.9-79.2 \%$ of the gap between the baseline (36\%) and the required target range $(60-70 \%$; see Figure 1). However, the gap closure is somewhat reduced because the 55\% constitute a "net" target: The Climate Law allows the crediting of LULUCF removals of up to $225 \mathrm{Mt} \mathrm{CO}$, so that the $55 \%$ target translates into an actual emission cut of $52.8 \%$ (EU, 2021). At the same time, the magnitude of the allowed LULUCF credits is somewhat lower than in the 2030 Framework. Furthermore, the Climate Law includes the requirement for the Commission to assess the consistency of each draft measure or legislative proposal with the climate-neutrality objective. Other flexibilities cannot be assessed yet since they will only be discussed as part of the further implementing legislation.

Concerning stringency, the Climate Law makes the 2030 and 2050 emission targets legally binding. While discussions so far would not point to a significant deviation from the existing stringency of the governance framework, relevant other aspects cannot be assessed yet as the implementing legislation is still under development.

Finally, the Climate Law further strengthens the existing ratcheting mechanism and thus the adaptability of the legislation. The schedule for review and potential upward revision of the legislation in line with the quintennial global stocktakes of the Paris Agreement is maintained. In addition, the Climate Law requires the Commission to formulate an emission reduction target for 2040 within six months after the first global stocktake in 2023, accompanied by an indicative Union GHG emission budget for 2030-2050 (EU, 2021). This 2040 target can be revised within six months of the second global stocktake in 2028. Lastly, a European Scientific Advisory Board will be established to provide scientific advice on the EU's existing and proposed measures, targets and GHG emission budget. Additionally, member states are invited to establish their own national climate advisory bodies.

Overall, the EGD thus seems to increase the farsightedness of EU CEP somewhat beyond the level of the 2020 Package. To be sure, the 2030 emission reduction target of $55 \%$ only achieves about the same level of alignment with the ideal ambition as the 2020 target of $20 \%$ (assuming stringency will remain roughly stable in the upcoming further implementing legislation). It is the process-related elements-the maturing of the long-term perspective and the strengthening of the ratcheting mechanism - that elevate the EGD above the 2020 Package. This assessment hinges on retaining the prior ideal ambition (of the 2030 Framework), which may be questioned given the increasing focus on limiting global temperature increase to $1.5^{\circ} \mathrm{C}$ after the Paris Agreement and the IPCC $1.5^{\circ} \mathrm{C}$ report (IPCC, 2018). When we calibrate the emission target toward a $1.5^{\circ} \mathrm{C}$ warming scenario, the EGD would appear to be even more myopic. In this case, the EU's ideal targets for 2030 and 2050 may have to be increased to $77-87 \%$ and to more than $140 \%$ (i.e., negative emissions) respectively (Robiou du Pont et al., 2017). As a result, the $55 \%$ target would only close the gap to the ideal emission reduction by some $37-46 \%$ (19 of 41-51 percentage points).

\subsection{Results}

The alignment of the EU's mid-term GHG emission targets with long-term requirements has fluctuated significantly from the 2020 Package to the EGD (see Figure 1). Despite the doubling of the nominal mid-term emission target from $20 \%$ by 2020 to at least $40 \%$ by 2030, the 2030 target was less aligned with long-term requirements (see Figure 1). Additionally, whereas the design of the 2020 Package ensured a significant overachievement of the $20 \%$ emission target, the 2030 Framework enhanced the flexibilities (in particular by including LULUCF offsets) so that a full realization or even an overachievement of the $40 \%$ emission reduction remained uncertain. Accordingly, the shortsight- 


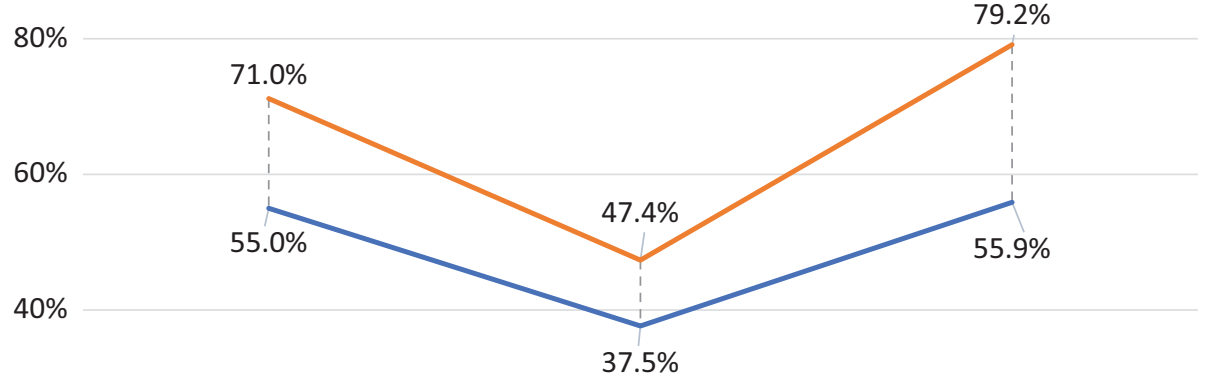

$20 \%$

$0 \%$
$20 \%$ by 2020
$40 \%$ by 2030
$55 \%$ by 2030
(2020 Package)
(2030 Framework)
(EGD)

Figure 1. EU mid-term GHG emission targets: closure of gap between baseline scenario and ideal target $(100 \%=$ complete closure).

edness of the mid-term emission target of the 2030 Framework may be considered to have been close to double that of the 2020 Package (60\% gap versus 30\% gap). The significant upgrade of the 2030 target to $55 \%$ under the EGD may only re-establish the level of farsightedness of the 2020 target, especially considering the reinforced inclusion of LULUCF removals. Admittedly, complementary elements required for a more complete assessment of the revised 2030 target under the EGD (including amendments to the rules governing the ETS, the effort sharing, RE and $E E$ ) are still to emerge from the further implementing legislation to be elaborated from mid-2021.

According to our assessment, the stringency of EU CEP has, so far, neither reinforced nor balanced the ups and downs in shortsightedness of ambition (see Table 1). Changes from the 2020 Package to the 2030 Framework have entailed both a weakening (e.g., Union target RE) and a strengthening of stringency (e.g., more procedural obligations), which seem to largely balance each other. We need to caution, though, that the assessment of the EGD necessarily remains incomplete on this aspect

Table 1. Evolution of the shortsightedness of the EU's climate and energy policy.

\begin{tabular}{|c|c|c|c|}
\hline & 2020 Package & 2030 Framework & Climate Law \\
\hline $\begin{array}{l}\text { Closure of gap } \\
\text { between baseline } \\
\text { and ideal scenario }\end{array}$ & $55-71 \%$ & $37.5-47.4 \%$ & $55.9-79.2 \%$ \\
\hline Stringency & $\begin{array}{c}\text { Relatively high } \\
\text { (formal legal status, precise } \\
\text { substantive and procedural } \\
\text { obligations, implementation } \\
\text { mechanisms) }\end{array}$ & $\begin{array}{l}\text { Equal } \\
\text { (abandonment of national RE } \\
\text { targets balanced by increase in } \\
\text { procedural obligations) }\end{array}$ & Not available yet \\
\hline Adaptability & $\begin{array}{l}\text { Limited } \\
\text { (potential increase of target } \\
\text { through ordinary legislative } \\
\text { procedure-no schedule) }\end{array}$ & $\begin{array}{c}\text { Strengthened } \\
\text { (five-year reviews tied to } \\
\text { global stocktakes of Paris } \\
\text { Agreement) }\end{array}$ & $\begin{array}{l}\text { Further strengthened } \\
\text { (additional provisions for } 2040 \\
\text { target and increased role of } \\
\text { science) }\end{array}$ \\
\hline Long-term thinking & $\begin{array}{l}\text { Limited } \\
\text { (vague long-term objectives, } \\
\text { no clear scientific basis or } \\
\text { mitigation pathway) }\end{array}$ & $\begin{array}{c}\text { Strengthened } \\
\text { (more specific long-term } \\
\text { objectives tied to Paris } \\
\text { Agreement) }\end{array}$ & $\begin{array}{c}\text { Further strengthened } \\
\text { (specific long-term objective } \\
\text { central to legislation) }\end{array}$ \\
\hline
\end{tabular}


as well, as it depends on the forthcoming implementing legislation.

At the same time, a long-term perspective and adaptability have seen steady growth over time (see Table 1). Long-term thinking has become more prominent in the legislation and the underlying positions of the European institutions from the 2020 Package, culminating in the inclusion of the 2050 climate-neutrality target in the European Climate Law. Furthermore, the 2030 Framework introduced scheduled reviews and upward revisions, which has been further strengthened in the EGD's Climate Law that frames a process for the establishment of a 2040 target as well as a GHG emission budget. It also promises to strengthen the link with science-a significant gap so far-through the creation of a European Scientific Advisory Body.

Overall, our assessment indicates that while the shortsightedness of EU CEP has evolved significantly, it has decreased far less than the development of the nominal mid-term emission targets might suggest. The substantive farsightedness of the EGD only re-established the levels of the 2020 Package (making good on the regression of the 2030 Framework). It is primarily due to the maturing of long-term thinking and the strengthening of the ratcheting mechanism, that EU CEP under the EGD can be considered less myopic than the 2020 Package (although the assessment remains preliminary pending the adoption of further implementing legislation). Additionally, using a $1.5^{\circ} \mathrm{C}$ warming scenario as the ideal scenario significantly increases the level of myopia of the EGD (and potentially also of the 2030 Framework). This raises the question whether such ideal levels of emission reduction are feasible domestically or whether they would require international action.

\section{Conclusion}

Our analysis reveals that the level of myopia of EU CEP displays significant variation over time. "Substantive myopia" (including the emission target and the stringency of accompanying policies) has decreased from the 2020 Package to the 2030 Framework before increasing under the EGD to levels comparable to the 2020 Package. In contrast, process-related elements (long-term perspective and adaptability) have advanced more linearly over time, while still leaving significant room for improvement. It remains to be seen whether the progress on adaptability will be able to overcome the enduring myopia of EU CEP. As time is running out to avoid the worst impacts of climate change, it may be questionable whether any future ratcheting can still catch up.

These findings make a significant contribution to both the literature on EU climate policy and research on temporal asymmetries, time inconsistencies and (democratic) myopia. It provides a novel perspective on EU climate policy that enables a diachronic assessment of policy development over time, properly integrating a long-term perspective that pays attention to time (in)consistency, which is central in climate policy. It also advances a systematic investigation of the level of myopia of (climate) policy as an essential basis for research on temporal asymmetries/inconsistencies and "democratic" myopia, thereby enabling comparisons across countries and across time as an important basis for advancing explanatory analyses.

A logical next step in advancing the research presented in this article may be the investigation of the driving forces of short- and farsightedness in general and with respect to EU CEP in particular. The aforementioned literatures on time asymmetries and democratic myopia might suggest a focus on institutional factors, whereas underlying interests and politics may also come into focus. For example, we might investigate in further detail the positions of the European institutions involved and the underlying politics as drivers of myopia. We may also scrutinize to what extent the applicable institutional procedures and structures have furthered or permitted a more science-based long-term perspective as opposed to more short-term political considerations. We are hopeful that our analysis creates a solid foundation for advancing such research to gain a deeper understanding of myopia in EU (climate) policymaking and how to overcome it.

\section{Acknowledgments}

This article has been prepared in the context of the Jean Monnet Network “Governing the EU's Climate and Energy Transition in Turbulent Times" (GOVTRANwww.govtran.eu) with the support of the Erasmus+ programme of the European Union, as well as the VUB's strategic research programme Evaluating Democratic Governance in Europe (EDGE). We would like to thank the three anonymous reviewers for their helpful comments and Didier Caluwaerts for his assistance in developing the framework.

\section{Conflict of Interests}

The authors declare no conflict of interests.

\section{References}

Averchenkova, A., Stern, N., \& Zenghelis, D. (2014). Taming the beasts of 'burden-sharing': An analysis of equitable mitigation actions and approaches to 2030 mitigation pledges (Policy Paper). Grantham Research Institute on Climate Change and the Environment.

Beckman, L. (2008). Do global climate change and the interest of future generations have implications for democracy? Environmental Politics, 17(4), 610-624.

Boasson, E. L., \& Wettestad, J. (2013). EU climate policy. Industry, policy interaction and external environment. Ashgate Publishing.

Brun, A. (2016). Conference diplomacy: The making of 
the Paris Agreement. Politics and Governance, 4(3), 115-123.

Burns, C. (2019). In the eye of the storm? The European Parliament, the environment and the EU's crises. Journal of European Integration, 41(3), 311-327.

Climate Action Tracker. (2019). Governments still showing little sign of acting on climate crisis. Warming projections global update. December 2019 (Policy Brief).

Council of the European Union. (2020). General approach European Climate Law (14171/20).

Cseh, A. (2019). Aligning climate action with the selfinterest and short-term dominated priorities of decision-makers. Climate Policy, 19(2), 139-146.

Delbeke, J., \& Vis, P. (2019). Towards a climate-neutral Europe. Routledge.

Delreux, T., \& Happaerts, S. (2016). Environmental policy and politics in the European Union. Palgrave Macmillan.

Dryzek, J. S., \& Niemeyer, S. (2019). Deliberative democracy and climate governance. Nature Human Behaviour, 3(5), 411-413.

Dupont, C. (2016). Climate policy integration into EU energy policy. Progress and prospects. Routledge.

den Elzen, M., \& Höhne, N. (2008). Reductions of greenhouse gas emissions in Annex I and non-Annex I countries for meeting concentration stabilisation targets: An editorial comment. Climatic Change, 91(3/4), 249-274.

EU. (2009a). Effort sharing decision (406/2009/EC).

EU. (2009b). Renewable energy directive (2009/28/EC).

EU. (2009c). ETS directive (2009/29/EC).

EU. (2012). Energy efficiency directive (2012/27/EU).

EU. (2018a). ETS directive ((EU) 2018/410).

EU. (2018b). LULUCF regulation ((EU) 2018/841).

EU. (2018c). Effort sharing regulation ((EU) 2018/842).

EU. (2018d). Governance regulation ((EU) 2018/1999).

EU. (2018e). Renewable energy directive ((EU) 2018/2001).

EU. (2018f). Energy efficiency directive ((EU) 2018/2002).

EU. (2021). European climate law ((EU) 2021/1119).

European Commission. (2008a). Proposal ETS directive (52008PC0016).

European Commission. (2008b). Proposal effort sharing decision (52008PC0017).

European Commission. (2016). Proposal effort sharing regulation (52016PC0482).

European Commission. (2018). EU and the Paris Climate Agreement: Taking stock of progress at Katowice COP (52018DC0716).

European Commission. (2020). Proposal European climate law (52020PC0080).

European Council. (2007). Presidency conclusions (7224/1/07).

European Environment Agency. (2007). Greenhouse gas emission trends and projections in Europe 2007. Tracking progress towards Kyoto targets.

European Environment Agency. (2010). Tracking progress towards Kyoto and 2020 targets in Europe.
European Environment Agency. (2014). Trends and projections in Europe 2014. Tracking progress towards Europe's climate and energy targets for 2020.

European Environment Agency. (2019). Trends and projections in Europe 2019. Tracking progress towards Europe's climate and energy targets.

European Parliament. (2008a). Report ETS directive (A60406/2008).

European Parliament. (2008b). Report effort sharing decision (A6-0411/2008).

European Parliament. (2017). Amendments effort sharing decision (P8_TA(2017)0256).

European Parliament. (2018). Amendments governance regulation (P8_TA(2018)0011).

European Parliament. (2020). Amendments European climate law (P9_TA(2020)0253).

Finnegan, J. (2019). Institutions, climate change, and the foundations of long-term policymaking (Working Paper). Grantham Research Institute on Climate Change and the Environment.

Galaz, V. (2019). Time and politics in the Anthropocene: Too fast, too slow? In F. Biermann \& E. Lövbrand (Eds.), Anthropocene encounters. New directions in green political thinking (pp. 109-127). Cambridge University Press.

Grant, N., Hawkes, A., Napp, T., \& Gambhir, A. (2020). The appropriate use of reference scenarios in mitigation analysis. Nature Climate Change, 10(7), 605-610.

Hayward, T. (2012). Climate change and ethics. Nature Climate Change, 2(12), 843-848.

Hovi, J., Sprinz, D. F., \& Underdal, A. (2009). Implementing long-term climate policy: Time inconsistency, domestic politics, international anarchy. Global Environmental Politics, 9(3), 20-39.

Howlett, M., \& Mukherjee, I. (2018). Routledge handbook of policy design. Routledge.

Intergovernmental Panel on Climate Change. (2001). Climate change 2001.

Intergovernmental Panel on Climate Change. (2007). Climate change 2007.

Intergovernmental Panel on Climate Change. (2018). Global warming of $1.5^{\circ} \mathrm{C}$.

Jacobs, A. M. (2016). Policy making for the long term in advanced democracies. Annual Review of Political Science, 19(1), 433-454.

Kulovesi, K., \& Oberthür, S. (2020). Assessing the EU's 2030 Climate and Energy Policy Framework: Incremental change toward radical transformation? Review of European, Comparative \& International Environmental Law, 29(2), 151-166.

Lacasta, N., Oberthür, S., Santos, E., \& Barata, P. (2010). From sharing the burden to sharing the effort: Decision 406/2009/EC on member state emission targets for non-ETS sectors. In S. Oberthür \& M. Pallemaerts (Eds.), The new climate policies of the European Union. Internal legislation and climate diplomacy (pp. 93-116). Brussels University Press. 
Levin, K., Cashore, B., Bernstein, S., \& Auld, G. (2012). Overcoming the tragedy of super wicked problems: Constraining our future selves to ameliorate global climate change. Policy Sciences, 45(2), 123-152.

Machin, A. (2019). Democracy and agonism in the Anthropocene: The challenges of knowledge, time and boundary. Environmental Values, 28(3), 347-365.

Mackenzie, M. K. (2016). Institutional design and sources of short-termism. In I. González-Ricoy \& A. Gosseries (Eds.), Institutions for future generations (pp. 24-48). Oxford University Press.

McLaren, D. (2020). Quantifying the potential scale of mitigation deterrence from greenhouse gas removal techniques. Climatic Change, 162(4), 2411-2428.

Meinshausen, M., Jeffery, L., Guetschow, J., Robiou Du Pont, Y., Rogelj, J., Schaeffer, M., Höhne, N., den Elzen, M., Oberthür, S., \& Meinshauses, N. (2015). National post-2020 greenhouse gas targets and diversity-aware leadership. Nature Climate Change, 5(12), 1098-1106.

Oberthür, S., \& Pallemaerts, M. (2010). The new climate policies of the European Union. VUB Press.

Oberthür, S. (2019). Hard or soft governance? The EU's
Climate and Energy Policy Framework for 2030. Politics and Governance, 7(1), 17-27.

Robiou du Pont, Y., Jeffery, L., Gütshow, J., Rogelj, J., Christoff, P., \& Meinshausen, M. (2017). Equitable mitigation to achieve the Paris Agreement goals. Nature Climate Change, 7(1), 38-43.

Rayner, T., \& Jordan, A. (2016). Climate change policy in the European Union. In Oxford research encyclopedia of climate science. Oxford University Press.

Rogelj, J., Chen, C., Nabel, J., Macey, K., Hare, W., Schaeffer, M., Markmann, K., Höhne, N., Krogh Andersen, K., \& Meinshausen, M. (2010). Analysis of the Copenhagen accord pledges and its global climatic impacts-A snapshot of dissonant ambitions. Environmental Research Letters, 5(3), Article 034013.

Torney, D., \& O'Gorman, R. (2020). Adaptability versus certainty in a carbon emissions reduction regime: An assessment of the EU's 2030 climate and energy policy framework. RECIEL, 29, 167-176.

Williston, B. (2019). The ethics of climate change: An introduction. Routledge.

Winkler, H., Vorster, S., \& Marquard, A. (2009). Who picks up the remainder? Mitigation in developed and developing countries. Climate Policy, 9(6), 634-651.

\section{About the Authors}

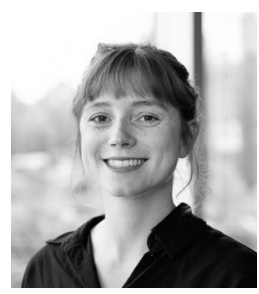

Jana Gheuens is a PhD researcher at the Brussels School of Governance at the Vrije Universiteit Brussel. Her PhD project explores the shortsightedness of the EU's climate and energy governance as part of the Vrije Universiteit Brussel's Evaluating Democratic Governance in Europe (EDGE) programme.

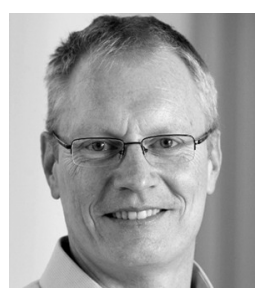

Sebastian Oberthür is professor of environment and sustainable development at the Brussels School of Governance at the Vrije Universiteit Brussel and professor of environmental policy and law at the Centre for Climate Change, Energy and Environmental Law at the University of Eastern Finland. Since the early 1990s, Sebastian has contributed to scholarship on a broad range of issues relating to international and European environmental, climate and energy governance. 